\title{
Urban Heat Islands in Relation to Green Land Use in European Cities
}

Key words: landscape metrics; land surface temperature; land use; MODIS; urban forest; urban heat island

\section{ABSTRACT}

The phenomenon of increased temperature in cities compared to their rural environs, also referred to as urban heat island, is one of the most evident anthropogenic climatic modifications. Introducing green spaces and vegetation is the fastest, simplest, and a highly effective way of mitigating and adapting urban temperature conditions. The primary goal of the presented research is to identify the interrelationship between urban heat island magnitude (UHIM) and urban green infrastructure extent, shape, and distribution on European scale comparing different green space planning traditions - planning families (PFs). The UHIM for the European cities was calculated based on a reconstructed MODIS LST dataset of a period of ten years.

The reasons for the arrangement of UHIMs according to PFs and green land use are not easily explained and are certainly influenced by a number of various conditions in different PFs. UHIM increases with the longitude of cities. In some of the PFs, the relation between the UHIM and land use proportion is characteristic for certain land uses, but a considerable difference between PFs regarding land use proportion with significant impact on UHIM can only be noted in case of a forest. The configuration and composition of the forest correlate with UHIM with statistical significance, but the share of the forest does not affect UHI in all PFs in the same way. While a higher proportion of forest, higher largest patch index, higher mean patch area, higher edge density and higher proportional landscape core is associated with a lower UHIM in the New member and Mediterranean $\mathrm{PFs}$, the relationship in other PFs is reversed.

Information on general patterns of UHIM occurrence in relation to urban green infrastructure characteristics could help urban planners and politicians introduce changes on the local level, which would help providing nature-based solutions for the mitigation of the UHI phenomenon.

\section{Introduction}

It is expected that by the year 2050, two thirds of the world's population will live in an urban environment, which is a significant increase compared to today's $54 \%$. In Europe, one of the most urbanized regions, $73 \%$ of the population lives in urban areas (United Nations, 2014). Consequently, it is of key importance to provide favourable living conditions including adaptation of cities to climate changes. A frequent cause of a reduced well-being in an urban environment is experiencing heat stress (Lafortezza et al., 2009). In cities, higher surface and air temperature is the consequence of physical aspects of urban landscape (land use, urban morphology, construction materials), anthropogenic heat contribution, and meteorological conditions (wind, humidity, sky view factor, radiation, precipitation etc.) (Rizwan et al., 2008; Kleerekoper et al., 2012; Martin, 2015). The phenomenon of increased temperature in cities compared to their rural environs is referred to as urban heat island (UHI) and is one of the most evident anthropogenic climatic modifications typical for condensed urban areas (Arnfield, 2003; Schwarz et al., 2011, 2012). By causing heat stress, UHIs influence well-being (Lafortezza et al., 2009) as well as urban ecosystem (Luo et al., 2007), average energy consumption, (Rizwan et al., 2008) and, consequently, pollution and social equity (Harlan et al., 2007).

The UHI effect can be reduced by making changes in built form, material selection, and land use proportion in cities in order to raise the albedo and cool the surroundings. In addition to increasing 
the share of water surfaces, the key instrument of mitigating urban heat islands is introducing green spaces and vegetation (Rizwan et al., 2008; Kleerekoper et al., 2012; Norton et al., 2015). Vegetation influences the cooling process due to evaporative cooling and shading surfaces which absorb shortwave radiation (Kleerekoper et al., 2012; Kong et al., 2014a).

Many studies use land surface temperatures (LST) for UHI identification and it is accepted as the first step in UHI analysis (Voogt \& Oke, 2003). The most frequently used data in UHI analyses are acquired from thermal infrared remote sensors with many advantages (continuity, spatial distribution, scale) over meteorological ground measurements of air temperatures. The definition of UHI also includes surface urban heat islands, as some authors name the UHIs defined by LST (Voogt \& Oke, 2003; Martin et al., 2015). According to numerous studies, the intensity of UHIs and their correlation with urban green infrastructure (UGI) is the highest in summer (Chang et al., 2007; Hamada \& Ohta, 2010; Imhoff et al., 2010; Li et al., 2011). A phenomenon that occurs as, due to their traits, certain surfaces cool their surroundings is called urban cool island (Cao et al. 2010; Vidrih and Medved, 2013; Chang et al., 2014; Feyisa et al., 2014). It mitigates heat stress of the UHI effect and thus improves citizens' well-being (Lafortezza et al., 2009).

According to various authors, the cooling effect of urban green areas can reach from 200 to $400 \mathrm{~m}$ (Tyrväinen et al., 2005; Hamada \& Ohta, 2010; Dugord et al., 2014; Feyisa et al., 2014; Monteiro et al., 2016), depending on their type and configuration. The magnitude of an UHI is the most strongly influenced by the share green spaces in the vicinity (Maimaitiyiming et al., 2014), however, their spatial distribution must also be considered (Zhou et al., 2011; Li et al., 2012; Maimaitiyiming et al., 2014). Studies have shown that a large aggregated, continuous green area more strongly contributes to the reduction of UHI magnitude, providing a greater cooling effect than smaller surfaces (Chang et al., 2007; Cao et al., 2010; Dugord et al., 2014; Maimaitiyiming et al., 2014). This has been determined using various indices of landscape metrics, most frequently patch density, edge density (Li et al., 2011; Zhou et al., 2011; Li et al., 2012; Kong et al., 2014b; Maimaitiyiming et al., 2014; Ward et al., 2016;), shape index (Cao et al., 2010; Li et al., 2011, 2012; Zhou et al., 2011; Feyisa et al., 2014; Kong et al., 2014a), neighbour distance (Zhou et al., 2011), aggregation index (Kong et al., 2014a), and other fragmentation metrics.

Among the types of green areas, the greatest cooling effect is provided by the share of forest surfaces (Oke, 1989; Hamada \& Ohta, 2010; Li et al., 2011; Zhou et al., 2011; Dugord et al. 2014, Kong et al. 2014a, 2014b). For example, following a 10-percent increase in forest vegetation, Kong et al. (2014a) observed a reduction of LST by $0.83{ }^{\circ} \mathrm{C}$ in the city of Nanjing in China. Due to ever growing climate difficulties, the attention and investments of cities are turning towards building a more resistant urban environment to warming and its consequences. Green interventions are the fastest, easiest and a very effective way for the mitigation and adaptation of city's temperature conditions and thermal environment (Ward et al., 2016). Both practitioners and politicians responsible for UGI planning should be informed on the properties of UGI and its spatial distribution that contribute to the reduction of the UHI effect the most in order to adjust their planning strategy, investments, and interventions accordingly (Zhou et al., 2011; Kong et al., 2014a).

1.) The primary goal of the presented research is to identify interrelationships between UHI magnitude (UHIM) and UGI extent, shape, and distribution on European scale in different planning traditions (planning families).

Numerous studies measure the extend of influence various parameters of green areas in a selected city have on UHI's intensity or size. Usually, they focus on size, shape, and vegetation composition of green areas, mainly on an individual urban green area or green areas within a selected city. However, there is a lack of studies that would address a larger region, such as Europe, through a longer period 
of time and would connect UHI's magnitude with UGI and planning policies in different planning families (PF) in Europe (Davies, 2016). The UGI components are not equally distributed across Europe regarding their share, land use category, and pattern and are sometimes the result of a planning tradition. We hypothesized that PFs have significant influence on distribution and magnitude of UHIs in relation to land use across Europe. There are only few studies addressing larger regions, whole continents (e.g. Imhoff et al., 2010; Zhang et al., 2010; Schwarz et al., 2011; Ward et al., 2016), or longer time periods (e.g. Li et al., 2004).

2.) The research identifies the correlation between UHIM and the proportion of green land use as well as urban forests' composition and configuration.

According to the findings of related studies, forests and other vegetated areas are the most effective cooling sources next to water (Zhang et al., 2010; Li et al., 2011). Our research focuses on urban forest characteristics in urban landscape.

\section{Data and Methods}

\subsection{Spatial Extent and City Boundaries}

The study covers areas within European Union with the exception of Croatia (Croatia entered the EU at the latest and therefore it has not yet been included in available data) and includes 403 European cities from Urban Audit (European Commission, Eurostat, 2014). For each of the cities, the administrative city area was used as city spatial extent in all subsequent spatial analyses. For the purpose of spatial analyses, cities with joint administrative boundaries were merged, which is why the sample in the presented analyses is adequately smaller $(\mathrm{N}=302)$.

\subsection{Land Surface Temperature and Urban Heat Island Magnitude}

For each of the cities, we calculated UHIM based on LST. We used a reconstructed MODIS LST dataset (produced by NASA), applying it to Europe as it is seamless and gap-free, with a temporal resolution of four records per day and enhanced at $250 \mathrm{~m}$ pixel resolution (Metz et al., 2014a). In a similar way as Rajasekar \& Weng (2009), we defined UHIM as the difference between the mean LST of the warmest quarter of the year and annual mean LST in a 10-year period (Metz et al., 2014b), measured above artificial surfaces within cities' local administrative units. Results represent the UHIMs in $\Delta T$ and ${ }^{\circ} \mathrm{C}$. UHIM per each of the cities was calculated in ArCMAP 10.5 (ESRI, 2017) using basic geoprocessing tools (e.g. Raster calculator/Minus and Zonal statistics as Table/Mean).

\subsection{City Land Use and Landscape Metrics of Urban Green Areas}

Certain land use characteristics based on Corine Land Cover (CLC) (European Environment Agency, 2012) were also calculated for each city area. For the purpose of our study, we used CLC in $100 \mathrm{~m}$ spatial resolution. 44 detailed CLC categories were combined into 5 broader main categories: artificial surfaces (CLC 1.1. - 1.3.), forests (CLC 3.1.), agricultural areas (CLC 2.1. -2.4.), urban green areas (CLC 1.4.1.-1.4.2.), and water areas (CLC 5.). This generalisation was needed for city land uses to be comparable across the whole EU study area.

Several landscape metrics were calculated for each city based on spatial distribution, proportions and shape of aforementioned main land use categories. The following metrics were used (see McGarigal et al., 2002 for details): edge density (edge length on a per unit area basis), Largest patch index 
(percentage of total landscape area comprised by the largest patch), mean patch area (average area size of patches) and proportional landscape core. SDMtools package in R was used to calculate these metrics.

\subsection{Other Explanatory Variables}

UHI magnitudes were additionally correlated with other explanatory data: (1) the distance from the city centre to the seacoast, and (2) longitude and latitude of the city centre.

The results of UHIMs and their relation to land use were discussed in the framework of different European Planning Families (PF). The framework was developed by Davies et al. (2015) in the GREEN SURGE project (FP7-ENV.2013.6.2-5-603567) and is based on a review of the existing European classification frameworks regarding different aspects of spatial, legal and social planning issues.All our UHI analyses were made according to the defined five main planning families (Fig. 1): British, Central, Mediterranean, New Member and Nordic PF. Description of cities' regional distribution is explained in Table 1.

The approach behind this study bases on the assumption that green infrastructure components (such as green spaces, forests,) are not equally distributed across European cities, PFs and, even more, that the population of the European cities do not all benefit from large amounts of green spaces and forests within their cities. Literature suggests that history and geographical location play a major role in current green space extent and spatial pattern so that northern, southern, western and eastern European cities differ in this respect (Larondelle et al. 2014). Urban land use is a result of complex factors and there are interactions with both biophysical characteristics and planning culture. Land use data is therefore crucial to explore processes behind urban land use and its function. In order to analyse the linkages between urban land-use, urban climate factors and urban planning traditions across a large sample of European cities, the research includes division on planning families (Eler et al., 2016). According to our hypothesis, PFs have a significant influence on distribution and magnitude of UHIs in relation to land use across Europe. Figure 1: The European Urban Audit cities and their planning families (adapted from Davies et al., 2015).

Table 1: Cities' distribution in planning families.

\subsection{Statistical Methods}

UHI magnitudes were related to land use and other explanatory variables using Pearson correlation coefficient. Significance of correlation was tested using correlation test. Correlation analyses were performed both for joint data and for each planning family separately.

PFs were also compared based on their UHI magnitudes using one-way ANOVA after checking for homogeneity of variances first. Tukey HSD test was performed after ANOVA to show the differences between specific PFs. All tests were performed at 0.05 significance level.

\section{Results and Discussion}

We determined that the correlation between UHIMs and different variables such as latitude, longitude, the proportion of different land uses and their landscape metrics differs according to PFs. Consequently, we discovered that in different PFs, the variables influence UHIMs differently. More interesting findings are:

- UHIM is higher in the northern cities. 
- The longitude of the cities has a stronger influence on UHIMs than latitude.

- A larger share of artificial areas and urban green areas increases the UHIM in the British PF.

- A higher share of agricultural land use reduces the UHIM in the Nordic and British PF and increases it in the Mediterranean PF.

- Forest composition and configuration do not affect the UHI in all PFs in the same direction.

- Connection between forest and UHIM is significant for all the PFs (except for the British PF).

- Higher proportion of forest is associated with a lower UHIM only in the New member and Mediterranean PFs.

- More fragmented and larger forest patches are in negative relationship with UHIM.

\subsection{City Position and Urban Heat Island Magnitude}

Before we focus on the influence of land use on UHIM, it is necessary to mention other variables strongly affecting UHIs. One of them is geographic position, which influences climate, PF classification, and characteristics of the proportion and distribution of land uses in cities. In the case of our study, the longitude of the study area has a stronger influence on UHIMs than its latitude (Fig. 2). As longitude grows, UHIM increases and while the connection between the variables is strong to very strong in the oceanic PFs (Nordic, British, Central) at $p<0.001$, it is moderate to strong in the Mediterranean and New member PF. In regard to these findings, we can conclude that the strongest influence can be ascribed to the distance of cities to the sea (especially the Atlantic), as it contributes to the reduction of temperature ecosystems (Fig. 2).

Latitude, on the other hand, has a significantly influence on UHIM in British and Nordic PF: the more to the north the city is positioned, the higher the UHIM in Nordic PF and lower in British PF (Fig. 2). A comparison of the connection between UHIM and PF reveals that UHIM is the highest in the New member (mean $10.6{ }^{\circ} \mathrm{C}, \mathrm{SE} 0.05$ ) and in Nordic PF (mean $10.2^{\circ} \mathrm{C}, \mathrm{SE} 0.34$ ) and the lowest in the British PF $\left(6.6^{\circ} \mathrm{C}, \mathrm{SE}\right.$ 0.17). In the middle are Central PF (mean $8.9^{\circ} \mathrm{C}, \mathrm{SE} 0.08$ ) and Mediterranean PF (mean $9.2^{\circ} \mathrm{C}, \mathrm{SE} 0.15$ ). Nordic and New member PF are not significantly different at 0.05 significance level nor are not different Central and Mediterranean PF. Similarly to Arnfield (2003) and Ward et al. (2016) who reported that warmer cities (e.g. Mediterranean PF) have lower heat magnitude compared to cooler cities (e.g. Nordic, British PF). It is, however, important to consider that some PFs encompass countries of very different latitudes (e.g. New member PF). Due to this inconsistency, we assess that different variables have a different influence on a PF. The reasons for the arrangement of the UHIMs according to PFs and green land use are not easily explained and are certainly influenced by a number of various conditions in different PFs.

Figure 2: Correlations between geographic position (longitude, latitude and distance to coast) and UHI magnitude for five planning families separately. Pearson coefficients of correlation and the corresponding significance of correlation ( $p$-value) are given.

\subsection{Relation between land use and UHIM}

The proportion of green and grey land uses varies with PFs (Fig. 3). The share of forests is the highest in the Nordic states (mean 0.334, SE 0.06) and lowest in the British PF (mean 0.042, SE 0.02). The highest share of artificial surfaces and green urban areas can be observed in the British PF. The highest share of agricultural areas was determined in the Mediterranean PF. According to the equal median of "all green" share (agricultural, urban green, and forest surfaces together) in all PFs, we assume that individual types of green land use have a different impact on UHIMs or that UHIMs are also affected by other factors.

Figure 3: Correlations between the share of different land uses and UHI magnitude for five planning 
families separately. Pearson coefficients of correlation and the corresponding significance of correlation ( $p$-value) are given.

However, in some PFs, certain land uses significantly influence the connection between UHIM and the share of land use. In the case of forest, the connection is significant for all the PFs $(p<0.05)$ except for the British PF, where the share of forest is considerably smaller. Instead, the UHIM in the British $\mathrm{PF}$ is significantly influenced by the share of artificial surfaces, urban green and agricultural areas in cities with a moderate connection between variables ( $r$ ). In the British PF, a larger share of artificial areas and urban green areas increases the UHIM. We assess that the share of urban green areas is strongly connected to the share of artificial surfaces, which is why it influences the UHIM in the same direction.

Similar correlations between the share of urban green areas and UHIM, can be found in the New member PF. The share of agricultural land use in cities does not influence UHIM in the same way in all the PFs either. While in the Nordic and in the British PF, a higher share of agricultural land use reduces the magnitude ( $r=-0.66$ Nordic $P F, r=-0.43$ British PF), it increases it in the Mediterranean PF with an otherwise weak connection between variables ( $r=0.27$ ) (Fig. 3). If we compare landscape metrics of agricultural land use in British and Mediterranean cities, the direction of influence on UHIM is always opposite (for example the largest patch index, mean patch area, proportional landscape core, landscape division index). The results generally show that a higher density of smaller and less complex patches of agricultural land use in the British PF increases UHIM in the British and decreases it in the Mediterranean PF. The reason for this is probably structural differences between the agricultural areas in the Mediterranean and the British PF, which results in a different albedo and consequently also in a different effect on the UHIMs. In the Nordic PF, the increase of the share of agricultural surfaces has the strongest influence on the reduction of UHIs.

\subsection{Forest Composition and Configuration and UHIM}

A considerable difference among PFs regarding land use proportion with a significant impact on UHIM is visible only in the case of forest (Fig. 3). Consequently, further analyses of PFs are presented focusing on the influence of forest areas. Forest configuration and composition correlate with UHI intensity with statistical significance (Fig. 3 and 4), which is consistent with previous studies (Kong et al., 2014a, 2014b; Zhou et al., 2011).

Figure 4: Relationship between selected landscape metrics showing spatial forest configuration and UHIM within different PFs. Pearson coefficients of correlation and the corresponding significance of correlation ( $p$-value) are given.

Surprisingly, the share of forest does not affect the UHI in all PFs in the same direction. While a higher proportion of forest is associated with a lower UHIM in the New member and Mediterranean PFs, the relationship in other PFs is reversed (Fig. 3). The results for the Nordic, British, and Central PF are comparable with the results of a study of 70 European cities during the heat wave in July 2006 (Ward et al., 2016), in which northern cities displayed a positive correlation between UHIM and the share of green areas, whereas southern cities displayed a neutral or negative correlation.

In addition to various climate differences between PFs, this anomaly can also be ascribed to a different forest type (Fig. 5). Considering the results of the study of an UHI in the city of Poznań, Poland (Majkowska et al., 2017) and the study of UHIs across biomes in the continental USA (Imhoff et al., 2010), coniferous forest contributes less to the reduction of LST than deciduous forest. The reason for this is lower albedo of coniferous forest compared to deciduous forest. The increase of UHIMs in the Nordic PF despite a large forest share could be explained with prevailing coniferous 
forest. In Mediterranean and New member PF, on the other hand, large forest surfaces reduce UHIM, as contrary to the Nordic PF, deciduous and mixed forest is prevalent. However, this theory does not explain mild increase of UHIM with growing forest share in the Central PF, despite the largest share of deciduous forest. The reasons for this anomaly are not entirely clear, as UHIM is influenced by a number of different variables beside forest composition and configuration. In addition, these variables differ regarding their influence on UHIs based on PFs.

Figure 5: The share of coniferous (A), broad-leaved (B), and mixed forest (C) within administrative city boundaries in five different planning families.

Maimaitiyiming et al. (2014) and Zhou et al. (2011) state that composition of green surfaces in cities influences LST more than their configuration. Our results show a similar significant relation between UHIMs and forest share (except the British PF), however, the connections between variables are weak to moderate. In addition to forest composition, certain indices of landscape metrics in some of the PFs significantly influence UHIM as well. These data on the PFs could be interesting for further strategic planning of urban green areas.

Forest configuration shows similar influence direction tendencies as composition - the Mediterranean and New member PFs show opposing influence directions as the rest of the PFs. The strongest connection between various forest configurations and UHIM is evident in the Nordic PF.

With the size of the city's largest patch index, mean patch area, higher edge density and share of forest patch core area (proportional landscape core), the UHIM increases in all but Mediterranean and New member PFs with a weak connection (Fig. 4). These results are not utterly consistent with the study by Dugord et al. (2014), who argue that in Berlin (Central PF), larger forest share and extensive, aggregated forest patches significantly reduce LST.

Negative correlations between forest share, forest patch density, edge density, forest mean patch area, and UHIM in the Mediterranean and New member PF are comparable with numerous studies of UHIs in Chinese cities with similar or smaller latitudes than Mediterranean (eg. Kong et al., 2014a; Li et al., 2011; Chen et al., 2006). Maimaitiyiming et al. (2014) give an example of Aksu city, China, and Zhou et al. (2011) an example of Baltimore, USA, where the latitude is similar to Mediterranean. They conclude that larger green surfaces with higher edge density and forests provide a greater cooling effect than a number of smaller surfaces with the same sum of the surface.

\subsection{Limitations of the Study}

The limitations of the study are similar of those reported by Schwarz et al. (2011), who used similar data and scale in their study. First, due to the extensive time period selected, instead of using raw LST data, we used reconstructed high-resolution LST from MODIS with $250 \mathrm{~m}$ spatial resolution. Due to the reconstruction, some of the LST extremes were consequently interpolated. Second, data provided by Corine Land Cover with $100 \mathrm{~m}$ spatial resolution are more precise LST. Accuracy of data for this large-scale analysis are good enough, however, more precise UHIs detection and delineation would be possible, due to higher resolution of temperature and land use data. This would facilitate studying the effect of green areas inside UHI and therefore the green infrastructure planning for climate adaptation at the individual city level. Some limitations were also met in the comparison of cities due to the use of administrative boundaries of the selected cities (Urban Audit), as these boundaries are not always set according to the same criteria.

\section{Conclusions}


The research concerning influence of land use on UHIM is set on a large study area comprised of European cities for a time period of ten years in order to determine general laws regarding the correlation of land use and UHIM in relation to planning families. Due to a diverse nature of the cities included in the research, different geographical position, specific impacts of water bodies, terrain, winds, climate, long time period of data gathering and UGI planning tradition, searching for correlations on the regional or continental level is challenging (Oke, 1989). Correlations between the selected variables are relatively small as determined by Schwarz et al. (2011) in the research of indicators for quantifying UHIs across Europe.

The study is unique by its sample size and time coverage comparing to other studies with smaler number of cities. Regarding the results is UHIM quite idiosyncratic. However, some patterns between $\mathrm{UHI}$, land use and other entities have been shown. The causes of UHIs are not shared through various PFs or cities. The reasons for the arrangement of UHIMs according to PFs and green land use are not easily explained and are certainly at least indirect influenced also by longitude and latitude of the cities, distance from coast and configuration of land uses. In general, it could be said that northern cities have a greater UHI magnitude (except the British PF). The correlation between the forest share and UHIM is significant in all the PF, except in the British, where UHIM increases with the growing share of artificial areas and urban green areas. Additionally, significant influence on UHIM is provided by the share of artificial surfaces, urban green areas, and agricultural areas within cities. In the Mediterranean PF, large portions of agricultural areas increase UHIM, while in the Nordic and British $\mathrm{PF}$ it reduces it. High proportions of forest are associated with a lower UHIM in the New member and Mediterranean PFs, while the relationship in other PFs is reversed. Similarly, the configuration of forest in these two PFs has the opposite effect compared to the rest of the PFs. This anomaly requires additional analyses in order to provide an explanation of the nature of its existence.

Although the findings are quite theoretical and in continental scale, it would be necessary to implement them on the possibilities of UHI reduction in the UGI planning in order to mitigate climate change. For example, Mediterranean cities' green infrastructure planning should give priority to larger and more fragmented green patches and Nordic cities could promote some agricultural land use in the cities.

Research is of key importance for the revelation of general patterns of UHIM occurrence according to urban green infrastructure characteristics and their further consideration at the local level. The findings related to influences of certain green areas, their composition and configuration could help urban planners and politicians introduce changes that would help provide nature-based solutions for the mitigation of the UHI phenomenon (Monteiro, 2016).

This study opens an opportunity and necessity for further research on differences between PFs and correlations with UHIs. There is need for more in-depth analyses of a selected region or cities, which could greatly contribute to the applied UGI planning. Equally welcome would be future confirmations of the determined correlations with another selection of UHI definition.

\section{Acknowledgements}

The research was funded by the GREEN SURGE, EU FP7 collaborative project, FP7-ENV.2013.6.2-5603567. 


\section{References}

Arnfield, A. J. (2003). Two decades of urban climate research: a review of turbulence, exchanges of energy and water, and the urban heat island. International journal of climatology, 23(1), 1-26.

Cao, X., Onishi, A., Chen, J., \& Imura, H. (2010). Quantifying the cool island intensity of urban parks using ASTER and IKONOS data. Landscape and urban planning, 96(4), 224-231.

Chang, C. R., \& Li, M. H. (2014). Effects of urban parks on the local urban thermal environment. Urban Forestry \& Urban Greening, 13(4), 672-681.

Chang, C. R., Li, M. H., \& Chang, S. D. (2007). A preliminary study on the local cool-island intensity of Taipei city parks. Landscape and Urban Planning, 80(4), 386-395.

Chen, X. L., Zhao, H. M., Li, P. X., \& Yin, Z. Y. (2006). Remote sensing image-based analysis of the relationship between urban heat island and land use/cover changes. Remote sensing of environment, 104(2), 133-146.

Davies C., Hansen R., Rall E., Pauleit S., Lafortezza R., De Bellis Y., Santos A., Tosics I. (2015). Green Infrastructure Planning and Implementation. The status of European green space planning and implementation based on an analysis of selected European city-regions. Green Surge project report 5.1. Retrieved from: http://greensurge.eu/workingpackages/wp5/files/D_5.1_Davies_et_al_2015_Green_Infrastructure_Planning_and_Implementation _v2.pdf (Accessed June 10, 2017).

Dugord, P. A., Lauf, S., Schuster, C., \& Kleinschmit, B. (2014). Land use patterns, temperature distribution, and potential heat stress risk-The case study Berlin, Germany. Computers, Environment and Urban Systems, 48, 86-98.

Eler K. et al. 2016. Functional linkages between urban green infrastructure, biodiversity and human well-being. Report D3.2. of Green Surge project (ENV.2013.6.2-5- 603567). Retrieved from: http://greensurge.eu/products/functional-linkages/ (Accessed December 10, 2017)

European Commission, Eurostat (2014). Urban Audit 2011-2014. Local Administrative Units. Retrieved from: http://ec.europa.eu/eurostat/web/gisco/geodata/reference-data/administrativeunits-statistical-units/urban-audit\#ua11-14 (Accessed March 10, 2017).

European Environment Agency (2012). Corine Land Cover 2000-2006 changes - Version 16 (04/2012) - Datasets -EEA. Retrieved from: http://www.eea.europa.eu/data-andmaps/data/corine-land-cover-2000-2006 (Accessed March 10, 2017)

Feyisa, G. L., Dons, K., \& Meilby, H. (2014). Efficiency of parks in mitigating urban heat isl

Hamada, S., \& Ohta, T. (2010). Seasonal variations in the cooling effect of urban green areas on surrounding urban areas. Urban forestry \& urban greening, 9(1), 15-24.

Harlan, S. L., Brazel, A. J., Darrel Jenerette, G., Jones, N. S., Larsen, L., Prashad, L., \& Stefanov, W. L. (2007). In the shade of affluence: the inequitable distribution of the urban heat island. In Equity and the Environment (pp. 173-202). Emerald Group Publishing Limited. 
Imhoff, M. L., Zhang, P., Wolfe, R. E., \& Bounoua, L. (2010). Remote sensing of the urban heat island effect across biomes in the continental USA. Remote sensing of environment, 114(3), 504-513.

Kleerekoper, L., van Esch, M., \& Salcedo, T. B. (2012). How to make a city climate-proof, addressing the urban heat island effect. Resources, Conservation and Recycling, 64, 30-38.

Kong, F., Yin, H., James, P., Hutyra, L. R., \& He, H. S. (2014a). Effects of spatial pattern of greenspace on urban cooling in a large metropolitan area of eastern China. Landscape and Urban Planning, 128, 35-47.

Kong, F., Yin, H., Wang, C., Cavan, G., \& James, P. (2014b). A satellite image-based analysis of factors contributing to the green-space cool island intensity on a city scale. Urban Forestry \& Urban Greening, 13(4), 846-853.

Lafortezza, R., Carrus, G., Sanesi, G., \& Davies, C. (2009). Benefits and well-being perceived by people visiting green spaces in periods of heat stress. Urban Forestry \& Urban Greening, 8(2), 97-108.

Larondelle N., Haase D., Kabisch N. 2014. Diversity of ecosystem services provisioning in European cities. Global Environmental Change 26, 119-129.

Li, J., Song, C., Cao, L., Zhu, F., Meng, X., \& Wu, J. (2011). Impacts of landscape structure on surface urban heat islands: a case study of Shanghai, China. Remote Sensing of Environment, 115(12), 32493263.

Li, Q., Zhang, H., Liu, X., \& Huang, J. (2004). Urban heat island effect on annual mean temperature during the last 50 years in China. Theoretical and Applied Climatology, 79(3), 165-174.

Li, X., Zhou, W., Ouyang, Z., Xu, W., \& Zheng, H. (2012). Spatial pattern of greenspace affects land surface temperature: evidence from the heavily urbanized Beijing metropolitan area, China. Landscape ecology, 27(6), 887-898.

Luo, Z., Sun, O. J., Ge, Q., Xu, W., \& Zheng, J. (2007). Phenological responses of plants to climate change in an urban environment. Ecological Research, 22(3), 507-514.

Maimaitiyiming, M., Ghulam, A., Tiyip, T., Pla, F., Latorre-Carmona, P., Halik, Ü., ... \& Caetano, M. (2014). Effects of green space spatial pattern on land surface temperature: Implications for sustainable urban planning and climate change adaptation. ISPRS Journal of Photogrammetry and Remote Sensing, 89, 59-66.

Majkowska, A., Kolendowicz, L., Półrolniczak, M., Hauke, J., \& Czernecki, B. (2017). The urban heat island in the city of Poznań as derived from Landsat 5 TM. Theoretical and Applied Climatology, 128(3-4), 769-783.

Martin, P., Baudouin, Y., \& Gachon, P. (2015). An alternative method to characterize the surface urban heat island. International journal of biometeorology, 59(7), 849-861.

McGarigal, K., Cushman, S. A., Neel, M. C., \& Ene, E. (2002). FRAGSTATS: spatial pattern analysis program for categorical maps. Computer software program produced by the authors at the University of Massachusetts, Amherst. Retrieved from: www.umass.edu/landeco/research/fragstats/fragstats.html (Accessed July 27, 2017) 
Metz, M., Rocchini, D., \& Neteler, M. (2014a). Surface temperatures at the continental scale: tracking changes with remote sensing at unprecedented detail. Remote Sensing, 6(5), 3822-3840.

Metz, M., Rocchini, D., Neteler, M. (2014b). Reconstructed MODIS land surface temperature dataset. Retrieved from: http://gis.cri.fmach.it/eurolst/ (Accessed March 10, 2017).

Monteiro, M. V., Doick, K. J., Handley, P., \& Peace, A. (2016). The impact of greenspace size on the extent of local nocturnal air temperature cooling in London. Urban Forestry \& Urban Greening, 16, 160-169.

Norton, B. A., Coutts, A. M., Livesley, S. J., Harris, R. J., Hunter, A. M., \& Williams, N. S. (2015). Planning for cooler cities: A framework to prioritise green infrastructure to mitigate high temperatures in urban landscapes. Landscape and Urban Planning, 134, 127-138.

Oke, T. R., Crowther, J. M., McNaughton, K. G., Monteith, J. L., \& Gardiner, B. (1989). The micrometeorology of the urban forest [and discussion]. Philosophical Transactions of the Royal Society B: Biological Sciences, 324(1223), 335-349.

Rajasekar, U., \& Weng, Q. (2009). Urban heat island monitoring and analysis using a non-parametric model: A case study of Indianapolis. ISPRS Journal of Photogrammetry and Remote Sensing, 64(1), 86-96.

Rizwan, A. M., Dennis, L. Y., \& Chunho, L. I. U. (2008). A review on the generation, determination and mitigation of Urban Heat Island. Journal of Environmental Sciences, 20(1), 120-128.

Schwarz, N., Lautenbach, S., \& Seppelt, R. (2011). Exploring indicators for quantifying surface urban heat islands of European cities with MODIS land surface temperatures. Remote Sensing of Environment, 115(12), 3175-3186.

Schwarz, N., Schlink, U., Franck, U., \& Großmann, K. (2012). Relationship of land surface and air temperatures and its implications for quantifying urban heat island indicators-An application for the city of Leipzig (Germany). Ecological Indicators, 18, 693-704.

Tyrväinen, L., Pauleit, S., Seeland, K., \& de Vries, S. (2005). Benefits and uses of urban forests and trees. In Urban forests and trees (pp. 81-114). Springer Berlin Heidelberg.

United Nations (2014). World Urbanization Prospects: The 2014 Revision, Highlights. Department of Economic and Social Affairs. Population Division, United Nations.

Vidrih, B., \& Medved, S. (2013). Multiparametric model of urban park cooling island. Urban forestry \& urban greening, 12(2), 220-229.

Voogt, J. A., \& Oke, T. R. (2003). Thermal remote sensing of urban climates. Remote sensing of environment, 86(3), 370-384.

Ward, K., Lauf, S., Kleinschmit, B., \& Endlicher, W. (2016). Heat waves and urban heat islands in Europe: A review of relevant drivers. Science of The Total Environment, 569, 527-539.

Zhang, P., Imhoff, M. L., Wolfe, R. E., \& Bounoua, L. (2010). Characterizing urban heat islands of global settlements using MODIS and nighttime lights products. Canadian Journal of Remote Sensing, 36(3), 185-196. 
Zhou, W., Huang, G., \& Cadenasso, M. L. (2011). Does spatial configuration matter? Understanding the effects of land cover pattern on land surface temperature in urban landscapes. Landscape and Urban Planning, 102(1), 54-63. 


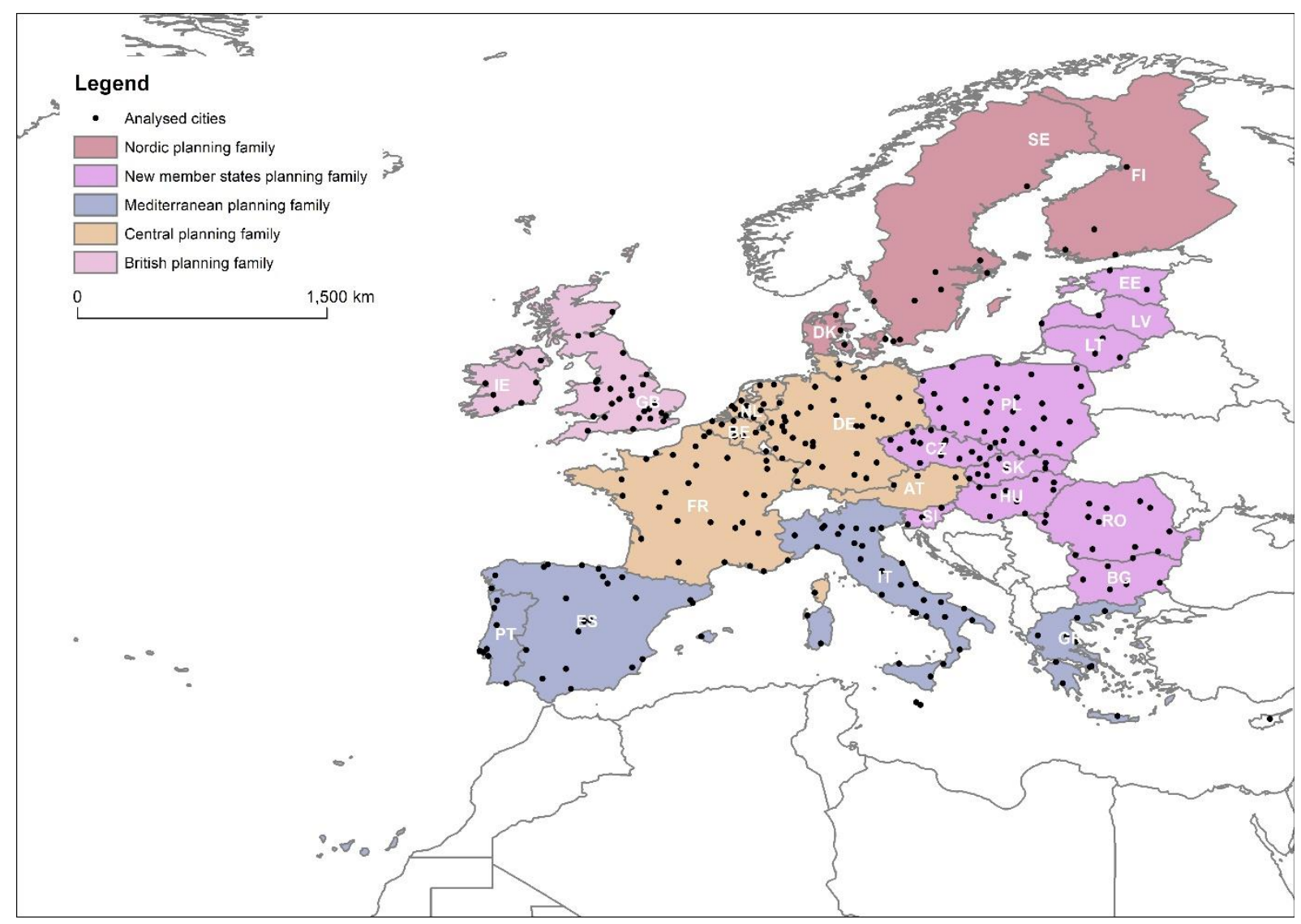

Figure 1: The European Urban Audit cities and their planning families (adapted from Davies et al., 2015). 

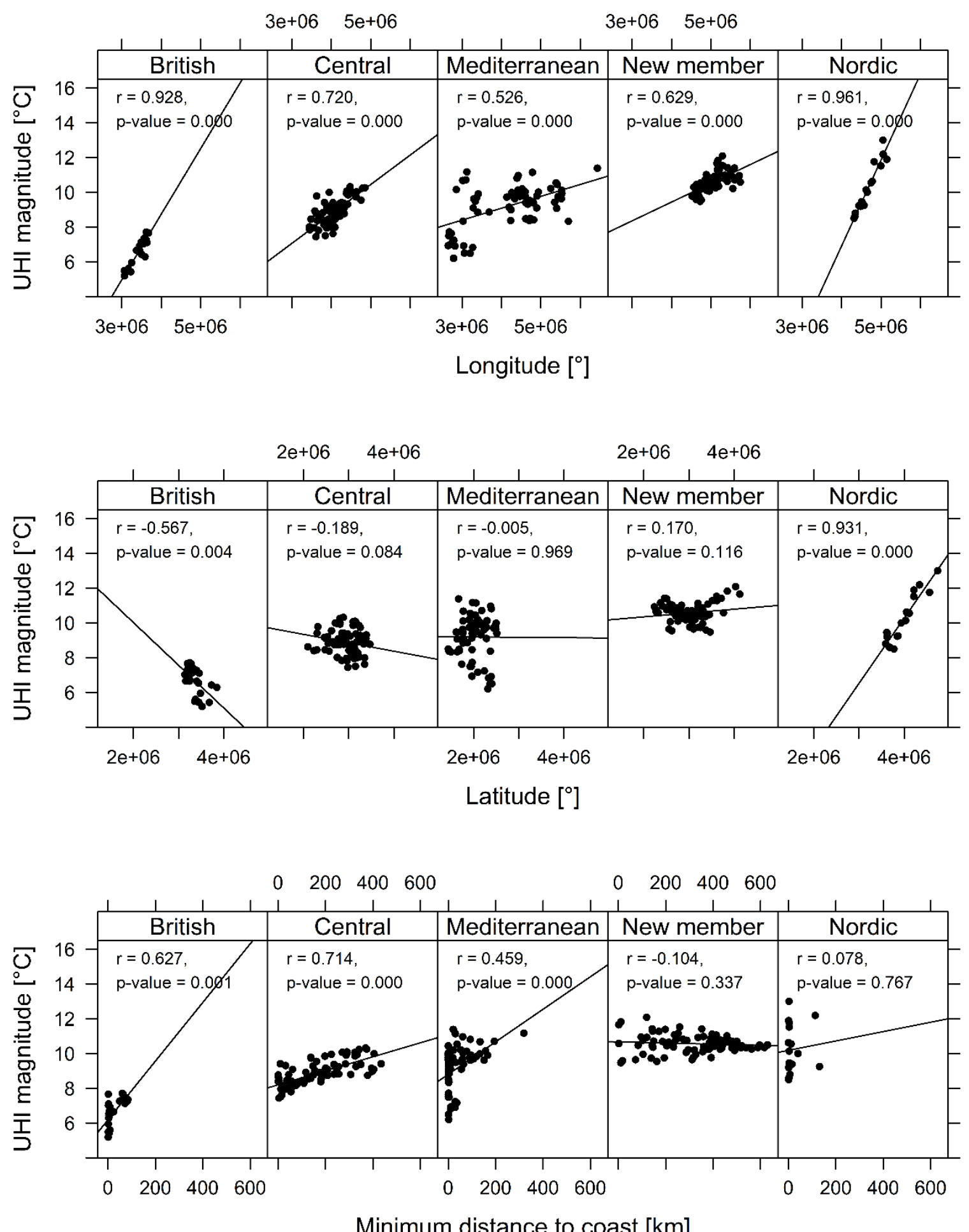

Figure 2: Correlations between geographic position (longitude, latitude and distance to coast) and UHI magnitude for five planning families separately. Pearson coefficients of correlation and the corresponding significance of correlation ( $p$-value) are given. 
$0 \quad 2040 \quad 60 \quad 80100$

$02040 \quad 60 \quad 80100$

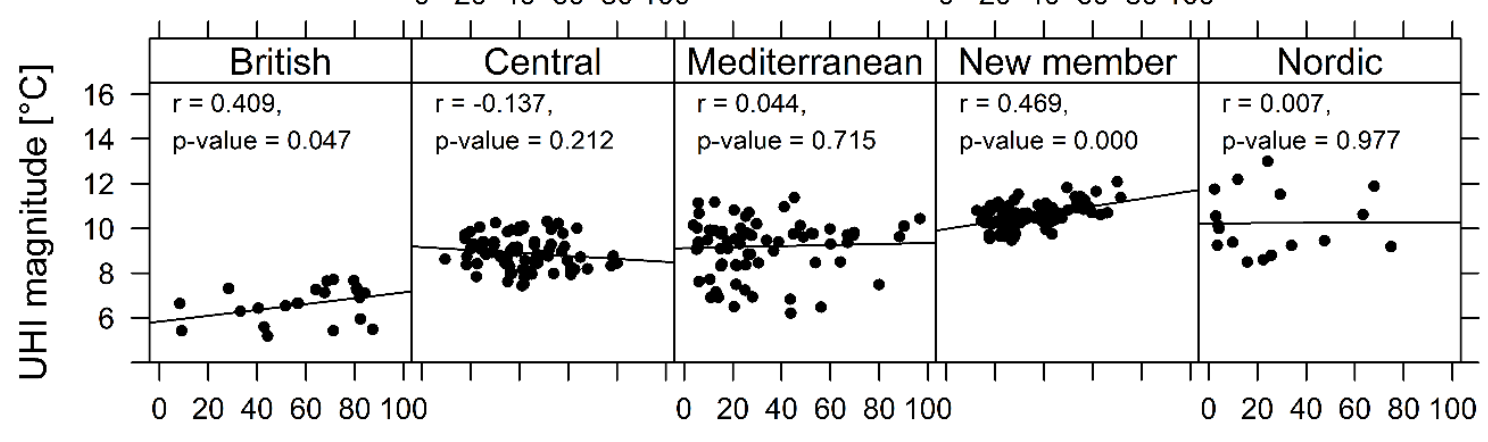

artificial areas in AM [\%]
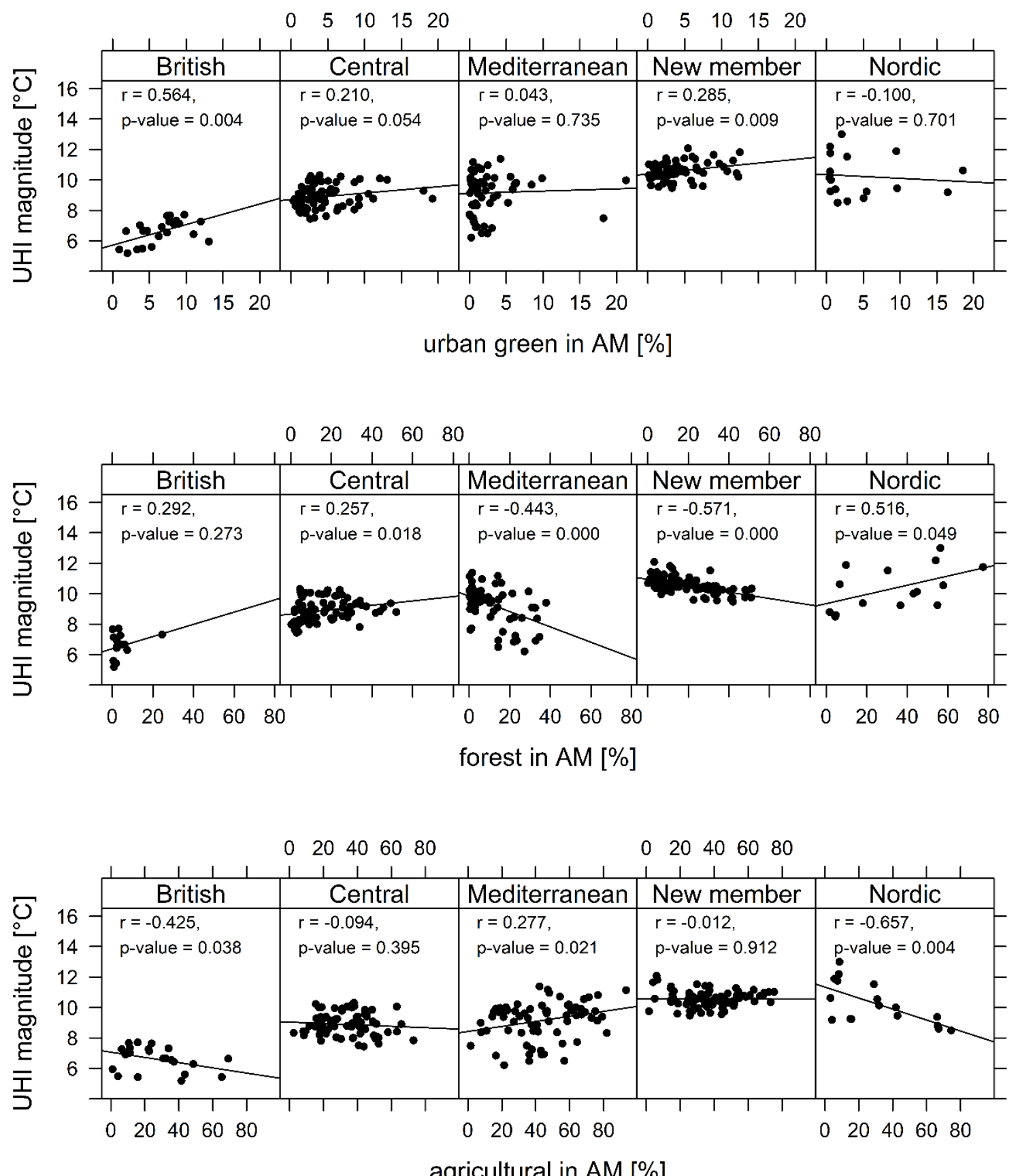
Figure 3: Correlations between the share of different land uses and UHI magnitude for five planning families separately. Pearson coefficients of correlation and the corresponding significance of correlation ( $p$-value) are given. 


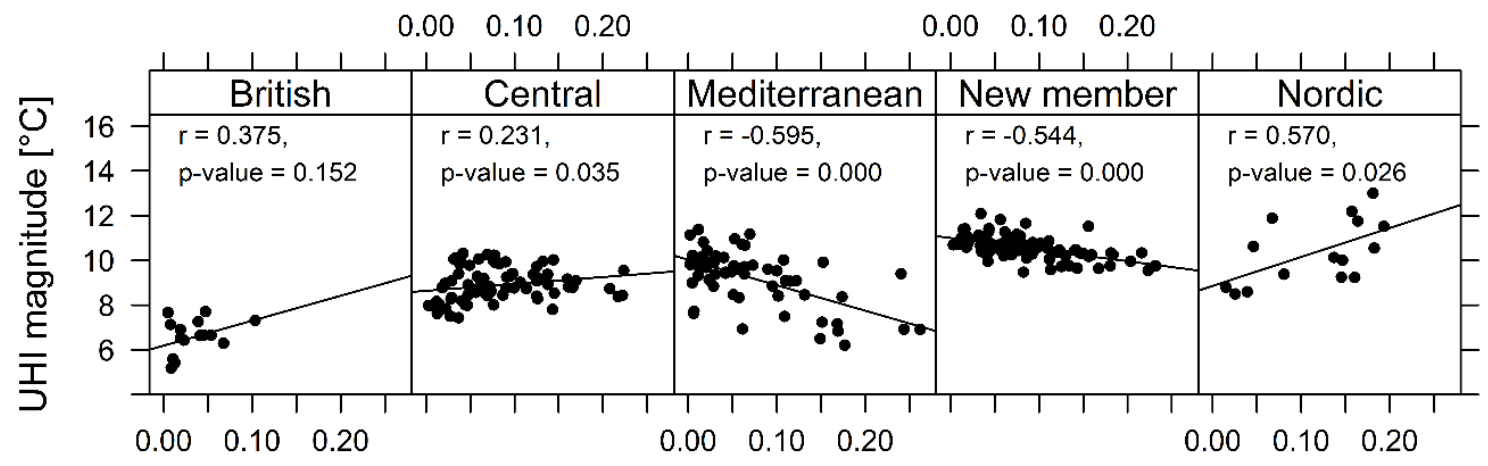

Edge density [m/m2]

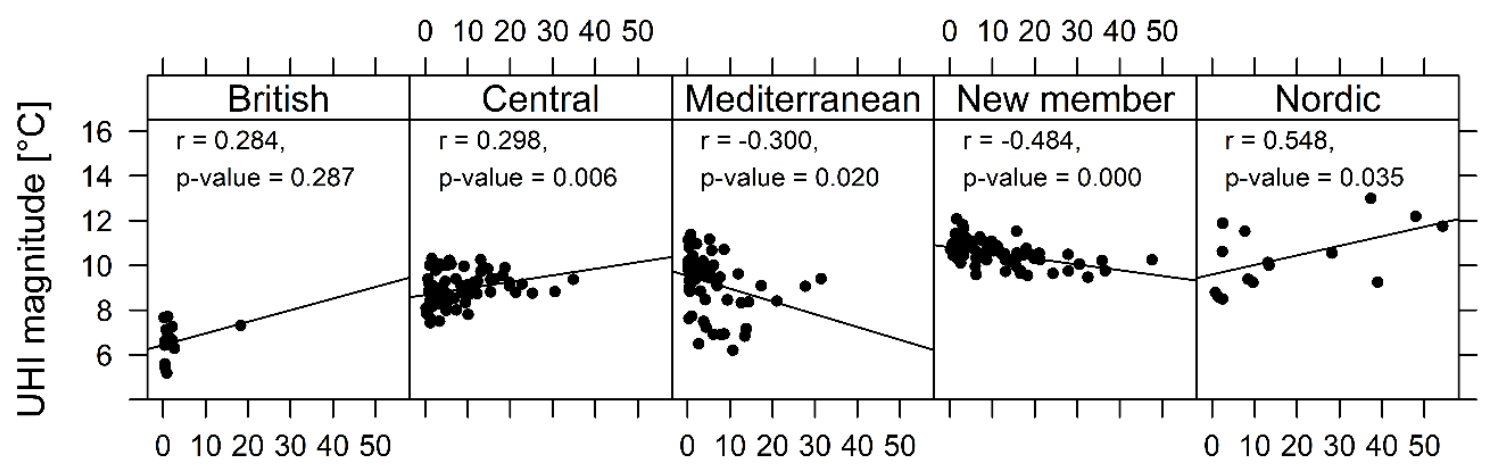

Largest patch index [\%]

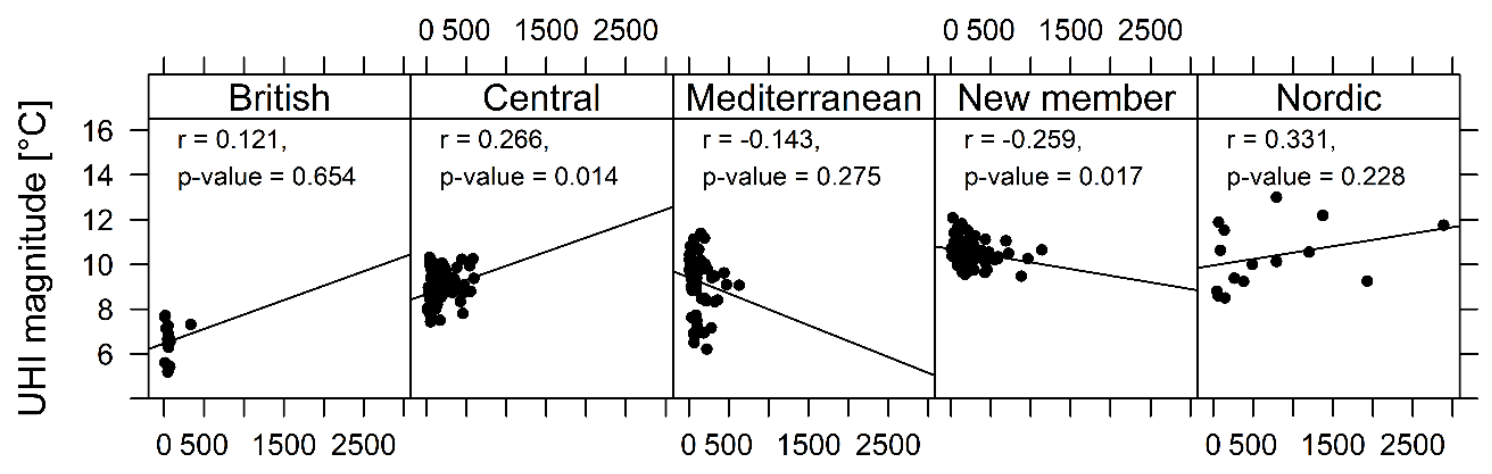

Mean patch area [ha]

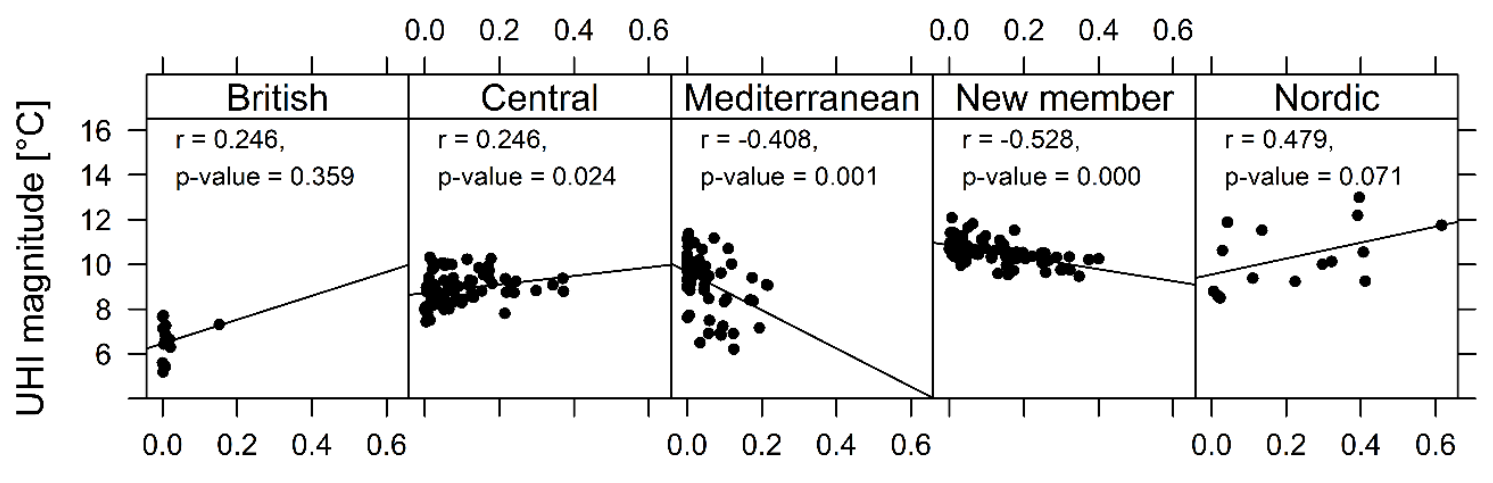

Proportional landscape core 
Figure 4: Relationship between selected landscape metrics showing spatial forest configuration and UHIM within different PFs. Pearson coefficients of correlation and the corresponding significance of correlation ( $p$-value) are given.
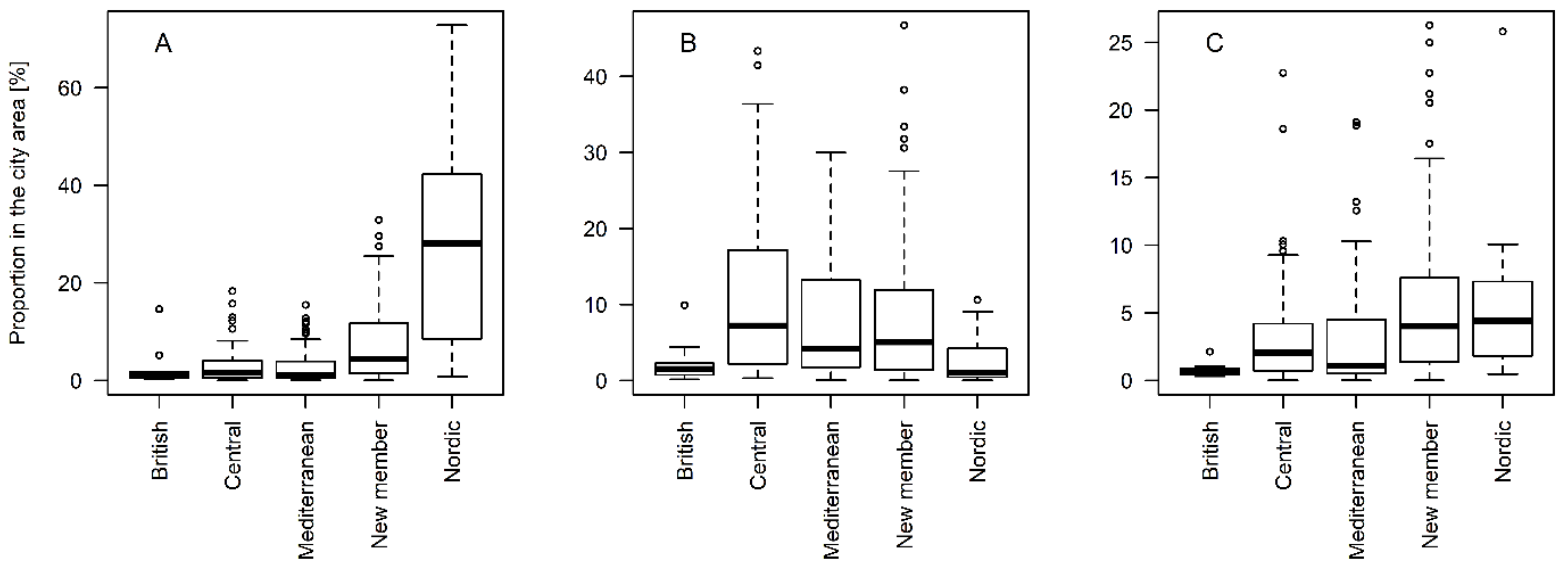

Figure 5: The share of coniferous (A), broad-leaved (B), and mixed forest (C) within administrative city boundaries in five different planning families. 
Table 1: Cities' distribution in planning families.

\begin{tabular}{|l|r|r|r|r|r|r|}
\hline Planning family & British & Central & Mediterranean & New member & Nordic & SUM \\
\hline No. of cities & 34 & 88 & 76 & 87 & 17 & 302 \\
\hline City area (\%) & 16,4 & 27,4 & 14,8 & 16,5 & 24,8 & 100,0 \\
\hline
\end{tabular}

